\title{
Cellular content of amniotic fluid as predictor of central nervous system malformations
}

\author{
MARTIN BOBROW, COLIN J. EVANS, JENNY NOBLE, AND \\ CHANDRAKANT PATEL
}

From the Oxfordshire Area Health Authority (T), Department of Medical Genetics, and Genetics Laboratory, Oxford University

SUMMARY Prospective observations on 442 consecutive samples have confirmed that pregnancies with CNS malformations are regularly associated with an abnormal cellular content of amniotic fluid. A crude semiquantitative test of the cell content can give valuable clinical information in relation to borderline amniotic fluid alpha-fetoprotein values, and help to detect false positive AFP's.

Amniotic fluid alpha-fetoprotein (AFP) estimations are widely used for the antenatal detection of neural tube closure defects. The spread of maternal serum AFP screening programmes, applied to whole populations of low-risk pregnancies, will generate an increasing number of referrals for amniocentesis (Wald and Cuckle, 1977). Amniotic fluid AFP estimation is a good predictor of fetal abnormality, but both false negative and apparent false positive results are known to occur, and any improvement in the diagnostic accuracy of amniocentesis would clearly be useful.

Sutherland et al. $(1973,1975)$ reported that amniotic fluid from pregnancies with neural tube defects contained abnormal numbers of a cell type resembling macrophages, and this work has recently been elaborated by a detailed description of the morphology of the cells concerned (Gosden and Brock, 1977).

We have routinely scored for the presence of a particular cell type in all amniotic fluid samples received in this laboratory for the past $1 \frac{1}{2}$ years, following a very simple procedure involving virtually no alteration from the standard system of amniotic fluid chromosome culture. We report here our observations on $\mathbf{4 4 2}$ samples from 426 consecutive patients.

\section{Materials and methods}

Samples of mid-trimester amniotic fluid were centrifuged. The supernatant was assayed for AFP by rocket immunoelectrophoresis. The cells were resuspended in Eagles MEM with 20\% FCS and inoculated into plastic culture flasks (Falcon) so that each flask contained \pm 50000 total cells in $1 \mathrm{ml}$ medium. On the following day (i.e. after 18 to 24 hours incubation at $37^{\circ} \mathrm{C}$ ) the flasks were inspected on an inverted phase contrast microscope. Preliminary observations on two anencephalic pregnancies and a number of normals had suggested that the cell types most characteristic of cases of CNS malformation were: (a) very elongated, highly refractile bipolar cells, sometimes with a small amount of membrane ruffling at the foot (Fig. 1a); and (b) a cell type with central nucleus, little cytoplasm, and three or more elongated processes. For brevity, both cell types will be referred to simply as 'abnormal' cells.

In the initial series of observations (Series A) flasks were scanned for the presence of these two cell types and were scored as negative if only an occasional such cell was seen, and positive if there were many such cells. Subsequently (Series B) a count was made of all such cells in 10 low power fields $(\times 60)$, the total abnormal cells $/ 10$ l.p.f. being recorded as the 'cell score' for that flask. Because cell density on the base of a culture vessel is non-random, three fields were counted at intervals up each long side of the flask and four fields up the centre.

The fluids received were taken for various indications, both chromosomal and related to potential CNS defects. Cell scores were routinely noted before AFP estimations on the liquor were available. Heavily bloodstained flasks were difficult to count and cell scores on these were rechecked after changing the medium at 3 to 4 days of culture time. The mean cell score per flask in normal fluids counted at $\mathbf{7 2}$ or $\mathbf{9 6}$ 


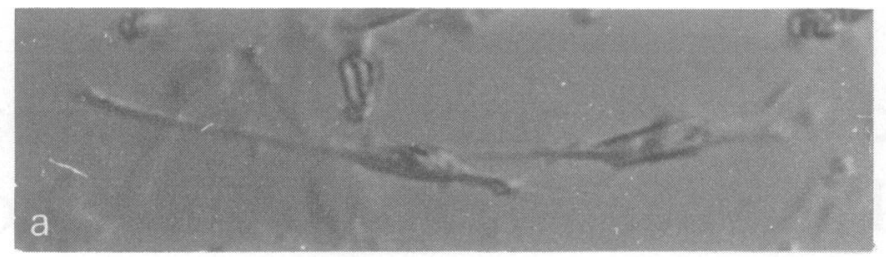

Fig. 1 (a) Typical cells from an anencephalic pregnancy (unstained, Nomarski interference contrast). (b) Representative cells from an apparently normal pregnancy with high cell count.

hours (1.41) was very similar to those counted at 24 hours $(1.52)$.

\section{Results}

We have observations relating to 442 amniotic fluid samples from 426 patients.

\section{SERIES A (TABLE 1)}

Of 168 samples received 8 had high numbers of 'abnormal' cells: 6 of these pregnancies were associated with high levels of AFP, and were found to have open CNS malformations. One was a repeat amniocentesis, the first sample not having abnormal cells. The remaining sample, which had relatively fewer cells, had a normal AFP level and has since delivered a normal infant.

One fluid with an AFP of $\pm 600 \mathrm{mg} / \mathrm{l}$ on two occasions did not contain an unusual number of elongated bipolar cells, and was the only fluid with a raised AFP and a normal cellular composition. Detailed pathological examination disclosed no detect-

Table 1 Cell content of amniotic fluids in relation to CNS malformation-numbers of pregnancies tested in various categories

\begin{tabular}{|c|c|c|c|c|}
\hline \multirow[b]{2}{*}{ Total case } & & \multirow[b]{2}{*}{ Cell score } & \multicolumn{2}{|c|}{ CNS malformation } \\
\hline & & & Present & Absent \\
\hline Series A & 168 & $\begin{array}{l}\text { +ve } \\
\text {-ve }\end{array}$ & $\begin{array}{l}6 \\
0\end{array}$ & $\begin{array}{r}2 \\
160\end{array}$ \\
\hline Series B & 258 & $\begin{array}{l}30 \\
30\end{array}$ & $\begin{array}{l}5 \\
0\end{array}$ & $\begin{array}{r}6 \\
247\end{array}$ \\
\hline Total & 426 & $\left\{\begin{array}{c}\text { High } \\
\text { Normal }\end{array}\right.$ & $\begin{array}{r}11 \\
0\end{array}$ & $\begin{array}{r}8 \\
407\end{array}$ \\
\hline
\end{tabular}

*196 pregnancies are still continuing, but have normal amniotic fluid AFP's. able abnormality in the aborted fetus. (A full descrip- $\overrightarrow{ }$ tion of this and other individual cases will be published separately.)

SERIES B (TABLES 1, 2 AND FIG. 2)

Cell counts are available for 463 flasks from 274 웅 amniotic fluids, taken from 258 different pregnancies. Duplicate flasks from the same amniotic fluid gave very highly correlated counts $(r=0.99)$. Replicate $\stackrel{\circ}{\Phi}$ counts by different observers on the same flasks also show a high degree of repeatability.

Sixteen samples $(5.8 \%)$ from 11 patients $(4.26 \%)$ had mean cell scores of more than 30 . Among these 11 . patients were 5 cases of CNS malformation, one intrauterine death, and two repeat amniocenteses in cases where the first sample taken had shown a normal cell score. Among pregnancies not known to have a neural tube defect, the frequency of cell scores above 30 was $6 / 253=2.4 \%$. The 11 separate flasks from pregnancies with CNS malformations gave cell scores from 40 to 1186 (mean 441 ).

Attention should be directed particularly to three $\frac{D}{O}$ aspects of our findings.

(a) Of 426 pregnancies tested in the combined data, $N$ 11 are known to have had neural tube malformations, $N$ and all of these were associated with raised numbers of $N$ elongated bipolar and multipolar cells.

(b) Of pregnancies without neural tube defects $2.6 \%$ had abnormally high cell scores. We were unable to distinguish, on phase contrast or on stained $\Phi_{\overparen{D}}$ preparations, the morphology of the cells present in these 'normal' pregnancies from those seen in $\frac{0}{0}$ association with CNS malformations (Fig. 1). Of the $8 \stackrel{\frac{}{\mathbb{D}}}{\circ}$ pregnancies with 'false positive' cell scores, 3 were in $\frac{?}{\Phi}$ repeat amniocenteses (the first sample in each case $\stackrel{\varrho}{\varrho}$ 
Table 2 Amniotic fluids with cell scores $>30$, not associated with CNS malformation

\begin{tabular}{|c|c|c|c|c|}
\hline Case no. & Cell score & $A F P(m g / l)$ & Pregnancy outcome & Comment \\
\hline $\begin{array}{l}76 / 87 \\
76 / 163\end{array}$ & \pm & $\begin{array}{l}20 \cdot 3 \\
11 \cdot 0\end{array}$ & $\begin{array}{l}\text { Normal } \\
\text { Normal }\end{array}$ & $\overline{\text { Repeat amniocentesis }}$ \\
\hline $77 / 6$ & 40 & 430 & IUD & Very cloudy fluid \\
\hline $77 / 48$ & 67 & 9.9 & Continuing & - \\
\hline $77 / 79$ & 175 & 9.0 & Continuing & - \\
\hline $77 / 80$ & 170 & 19.2 & $\begin{array}{l}\text { Terminated- } \\
\text { monosomy } 4 p\end{array}$ & Repeat tap* \\
\hline $77 / 108$ & 290 & 59.0 & & Repeat taps* of same \\
\hline 112 & 350 & 34.6 & Continuing & pregnancy-heavy fetal \\
\hline 124 & 150 & 20.9 & & blood contamination \\
\hline $77 / 195$ & 43 & 9.3 & Continuing & Very cloudy fluid \\
\hline
\end{tabular}

*First sample had normal cell content.

having had a normal cell count) and one was an intrauterine death.

(c) Eighteen pregnancies in the combined series gave a high amniotic fluid AFP ( $>5$ SD above mean). They were associated with the following fetal abnormalities: neural tube defects (11); trisomy 13 with scalp defect (1); intrauterine death (2); fetal bleed into amniotic fluid (1). Three pregnancies with high AFP's produced apparently normal fetuses. (In one of these, a resorbing twin may have been present.) Abnormal cell scores were recorded in all pregnancies with neural tube defects, in one case of intrauterine death, and in repeat samples from the case with fetal bleeding. The three unexplained high AFP's associated with no fetal abnormality all had clearly normal cell scores.

\section{Discussion}

Our prospective study of 442 amniotic fluids is in general agreement with previous workers (Sutherland et al., 1973, 1975; Gosden and Brock, 1977), that morphological study of cell types in the amniotic fluid can provide valuable information on fetal CNS abnormalities. It appears to have a particular place in assessing borderline high amniotic fluid AFP levels, in the interpretation of samples contaminated with fetal blood, and in indicating the rare unexplained false positive high AFP's. In the present series, 3 apparently normal fetuses were terminated on the basis of high amniotic fluid AFPs, and all of these were associated with normal cell scores.

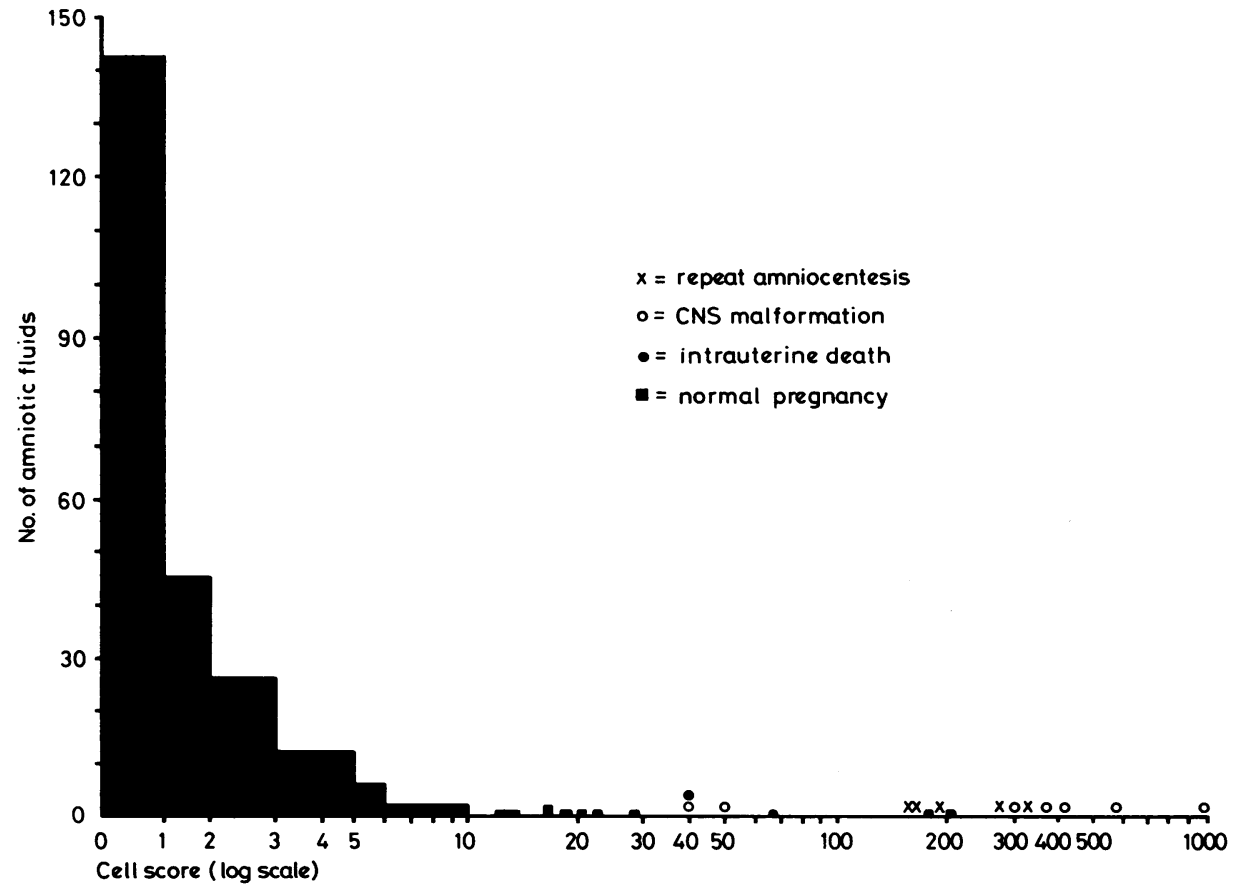

Fig. 2. Distribution of cell scores in cases of Series $B$ (log scale on $X$ axis). 
Like Sutherland et al. (1975), but unlike Gosden and Brock (1977), we found a substantial proportion of pregnancies with a high cell score $(8 / 19,42 \%)$ which were not associated with CNS malformations. Some of these are associated with repeat amniocenteses, and we have thrice witnessed conversion of a normal to a high score on repeat amniocentesis. Cell content should, therefore, not be scored on repeat amniocentesis. One intrauterine death was also associated with a moderately high cell score. Excluding these, the number of 'unexplained' false positive cell counts was $4 / 426$ cases tested $(0.9 \%)$.

Because we seed each flask with about 50000 cells, our cell scores are to some extent automatically adjusted for total cell concentration of the original sample; calculating the abnormal cells as a proportion of total settled cells, or of the total cell count in the original fluid, made no difference to our results. Gosden and Brock calculated the relevant cell types as a proportion of viable cells in the original sample, and claimed that this eliminated false positive results, though they do not give the total and viable cell counts on which this conclusion is based. The choice of more elaborate denominators may affect some borderline results, but we find it difficult to believe that they would separate out cell scores in the 100-200 range (see Fig. 2). Amniotic fluid generally contains about $20 \%$ viable cells, and these samples would need to contain virtually $100 \%$ viable cells to produce the fivefold difference in adjusted scores necessary to bring them down to within normal limits. Further data will resolve this point. Further elucidation of the nature and origin of the cells concerned may also help to distinguish false from true positive results. Though they certainly have some resemblance to macrophages (Sutherland et al., 1975), the evidence is not yet conclusive, and the problem of cell heterogeneity also exists.

Gosden and Brock (1977) characterised five cell types in amniotic fluid, and named four of these as particularly associated with neural tube defects. The first two of these four, the 'long bipolar cell' and the 'cell with multiple filamentous processes', clearly correspond to the cells which we have been scoring. We have also seen the other cell types described, but have not regularly counted them, as they appear to us more difficult to distinguish from cell types present in normal amniotic fluids. These authors scored fixed and

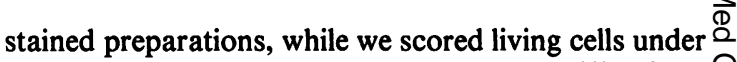
phase contrast. The cell types described differ from $\mathbb{\Phi}$ one another in such gross characteristics that there is no reason to believe that they cannot be satisfactorily $\stackrel{+}{\cdot}$ distinguished by phase contrast microscopy. This $\overrightarrow{\vec{F}}$ eliminates the need for specially plating and processing $\frac{-}{0}$ cells for scoring, and enables all available material to $\frac{\mathrm{C}}{-}$ be used for chromosome culture. The particular values $\frac{\bar{\sigma}}{\bar{n}}$ which we obtain for our cell scores are unlikely to be $\widehat{\Phi}$ precisely transferrable to other laboratories with different culture regimens, but it should be fairly easy $\omega$ to establish norms within each laboratory.

Any reduction in the probability of recommending the termination of a normal fetus is obviously $\vec{\sigma}$ important, both in the conventional clinical sense and in its impact on the overall acceptability of serum AFPO screening programmes. Some simple programme of $\vec{G}$ inspecting the cellular content of amniotic fluids $\mathrm{N}$ appears to give useful information for little effort, and 0 ought to be instituted as routine practice in $ᄋ$ laboratories dealing with amniotic fluids for antenatal ${ }_{-}$ diagnosis of fetal malformations.

We thank many obstetricians who referred samples to our laboratory, and our colleagues in the Oxford $\vec{\varphi}$ antenatal diagnostic clinic, particularly $\operatorname{Dr} R \mathrm{H}^{\infty}$ Lindenbaum, $\mathrm{Mr} \mathrm{G}$ Stirrat, and Professor A $\mathrm{C}$ Turnbull; and Miss S Kerr and Mrs A Naylor. Dr Jean Keeling performed necropsies on several of the aborted fetuses.

\section{References}

Gosden, C. M., and Brock, D. J. H. (1977). Morphology of rapidly adhering amniotic-fluid cells as an aid to the diagnosis of neural-? tube defects. Lancet, 1, 919-922.

Sutherland, G. R., Brock, D. J. H., and Scrimgeour, J. B. (1973) Amniotic-fluid macrophages and anencephaly. Lancet, 2, 10981099.

Sutherland, G. R., Brock, D. J. H., and Scrimgeour, J. B. (1975). Amniotic fluid macrophages and the antenatal diagnosis of anencephaly and spina bifida. Journal of Medical Genetics, 12,으 135-137.

Wald, N. J., and Cuckle, H. (1977). Maternal serum-alphafetoprotein measurement in antenatal screening for anencephaly and spina bifida in early pregnancy. Lancet, 1, 1323-1332.

Requests for reprints to Dr Martin Bobrow, Department of Medical Genetics, Oxfordshire Area Healtho Authority (Teaching), Old Road, Headington, OxfordN OX3 7LE. 